\title{
TRATAMENTO DE ÁGUA POR BIOSSORÇÃO UTILIZANDO CONSÓRCIO BACTERIANO DO SOLO *
}

\author{
Elena Kalinin Toss ${ }^{1}$ \\ Marcela dos Passos Galluzzi Baltazar² \\ Denise Crocce Romano Espinosa ${ }^{3}$ \\ Jorge Alberto Soares Tenório 4
}

\section{Resumo}

Inúmeras indústrias necessitam de sistemas de tratamento de água que favoreçam o processo de descarte de seus efluentes, além do aproveitamento do reuso de água. A mineração e siderurgia podem apresentar rejeitos com metais, que necessitam de tratamentos econômicos e sustentáveis. A biossorção é um exemplo de técnica que vem ganhando interesse em diversas áreas da pesquisa. $O$ objetivo do estudo foi avaliar a porcentagem de remoção de íons de níquel de uma solução monoelementar de cloreto de níquel II ( $\left.\mathrm{NiCl}^{2+}\right)$ em pH 2, 4 e 6. Para isso, utilizou-se um sistema de batelada, e $1 \mathrm{~g}$ de consórcio bacteriano liofilizado (sem ser autoclavado) isolado de amostra de terra. Os resultados indicaram que a eficiência da biossorção foi maior para o $\mathrm{pH} 6$, e que o consórcio bacteriano foi eficiente na remoção de íons de $\mathrm{Ni}^{2+}$.

Palavras-chave: Biossorção; Níquel; Consorcio Bacteriano; Reuso de Água; Biotecnologia.

\section{WATER TREATMENT BY BIOSORPTIUM USING BACTERIAL SOIL CONSORTIUM}

\section{Abstract}

Numerous industries need water treatment systems that favor the process of disposal of their effluents, besides the use of water reuse. Mining and metallurgy may present tailings with metals, which require economical and sustainable treatments. Biosorption is an example of a technique that has gained interest in several areas of research. The objective of the study was to evaluate the percentage of nickel removal from a monoelement solution of nickel chloride $\mathrm{II}\left(\mathrm{NiCl}^{2+}\right)$ at $\mathrm{pH} 2,4$ and 6 . For this purpose, was used the batch system and 1 gram of lyophilized bacterial consortium (without being autoclaved) isolated from soil sample. The results indicated that the biosorption efficiency was higher for $\mathrm{pH} 6$, and that the bacterial consortium was efficient in the removal of $\mathrm{Ni}^{2+}$ ions.

Keywords: Biosorption; Nickel; Bacterial Consortium; Water reuse; Biotechnology.

1 Engenheira Química, Mestranda do Departamento de Engenharia Química, Escola Politécnica da Universidade de São Paulo, São Paulo, São Paulo, Brasil.

2 Química, Doutora em Engenharia Química, Escola Politécnica da Universidade de São Paulo, São Paulo, São Paulo, Brasil.

3 Engenheira Metalurgista, Doutra em Engenharia Metalúrgica, Professora Associada, Departamento de Engenharia Química, Escola Politécnica da Universidade de São Paulo, São Paulo, São Paulo, Brasil.

4 Engenheiro Metalurgista, Doutor em Engenharia Metalúrgica, Professor Titular, Departamento de Engenharia Química, Escola Politécnica da Universidade de São Paulo, São Paulo, São Paulo, Brasil. 


\section{INTRODUÇÃO}

Um dos motivos para a forte pressão nos recursos hídricos é o desenvolvimento industrial em regiões de escassez de água (1). Como alternativa ao atendimento de demandas de recurso, escassez temporal de abastecimento, regulamentos de descarte e condições de seca em áreas úmidas, a aplicação de reutilização de água foi atribuída (2). A necessidade de uma gestão sustentável da água está relacionada a possíveis consequências da demanda desse efluente (3).

Dentre os papéis que a água desempenha, está o bem estar de indivíduos (4). A qualidade com que o efluente é descartado é um fator de impacto na biota. Inúmeros processos apresentam metais em seus efluentes. Se os metais estiverem acima dos níveis nutricionais permitidos, tornam-se tóxicos e a contaminação de solos por esses metais tem impacto na saúde humana $(5,6)$. O níquel é um metal que gera preocupação devido sua acumulação e limites de descarte foram estipulados, devido aos efeitos tóxicos (7).

Matérias-primas envolvidas no processo, como por exemplo, metais, inúmeras vezes acabam sendo descartadas porque a recuperação por técnicas tradicionais torna-se inviáveis devido ao custo do tratamento. Dentre processos viáveis de remoção de metais da água estão a adsorção e a abordagem biológica $(7,8)$. Assim, a técnica da biossorção vem ganhando cada vez mais interesse nos últimos anos por ser uma biotecnologia econômica, que contém metais na ordem de 1 a $100 \mathrm{mg} / \mathrm{L}$ (9).

Desta maneira, a biossorção está presente em estudos realizados por pesquisadores, além da aplicabilidade em setores de pesquisa de algumas indústrias, que estudam a eficiência da técnica e a busca por melhores parâmetros para utilização em processos industriais. A biossorção utiliza biomassas como bactérias, fungos, e algas, por meio de propriedades sequestradoras de metal (9). Dentre as vantagens da biossorção destacam-se o baixo custo operacional e a minimização do volume de rejeitos (10). Assim, o objetivo do trabalho foi avaliar a porcentagem de remoção de íons metálicos de níquel por meio da técnica de biossorção em sistema de batelada e a aplicabilidade de um consórcio bacteriano isolado da terra na remoção dos íons metálicos da solução monoelementar sintética.

\section{MATERIAIS E MÉTODOS}

\subsection{Preparação de soluções de níquel}

Foi preparada uma solução estoque sintética monoelementar de $10.000 \mathrm{mg}^{\mathrm{L}}{ }^{-1}$, que posteriormente foi filtrada por meio de filtro de membrana de $0,22 \mu \mathrm{m}$ e mantida em um refrigerador. Para obter as concentrações desejadas, diluições da solução estoque foram realizadas.

\subsection{Amostras de terra}

Amostras de terra foram coletadas da cidade de Cubatão, no estado de São Paulo, e foram armazenadas em um refrigerador. 


\subsection{Procedimento bacteriano}

\subsubsection{Meio de Cultura}

O meio de cultura das amostras de terra constou da utilização de erlenmeyer de 250 $\mathrm{mL}$, esterilizado, contendo $100 \mathrm{~mL}$ de meio Luria bertani (meio LB), $1 \mathrm{~g}$ de terra e $100 \mathrm{mg} \cdot \mathrm{L}^{-1} \mathrm{NiCl}_{2}$.

\subsubsection{Centrifugação}

Estas amostras de cultura bacteriana foram centrifugadas, separando 0 sobrenadante do consórcio bacteriano. O sobrenadante foi descartado, e o consorcio foi centrifugado três vezes com uma solução de $\mathrm{NaCl} 0,9 \%$. Após isso, as bactérias foram abastecidas a $-80^{\circ} \mathrm{C}$ com solução salina de $0,9 \%$ e água milli-Q.

\subsubsection{Liofilização}

Após o armazenamento da bactéria em $-80^{\circ}$ com a solução salina de $0,9 \%$, as bactérias foram liofilizadas até estarem secas. O processo de liofilização garante a retirada de umidade do consórcio bacteriano, e a morte parcial deste. As bactérias não foram autoclavas, portanto, só foram parcialmente mortas. A autoclavagem é que garante a completa morte do consórcio bacteriano.

\subsection{Estudos de biossorção por meio da técnica de batelada}

\subsubsection{Ensaios de batelada}

Os experimentos de batelada foram realizados em erlenmeyers de $125 \mathrm{~mL}$ contendo $50 \mathrm{~mL}$ de água milli-Q, $100{\mathrm{mg} . \mathrm{L}^{-1}} \mathrm{de} \mathrm{Ni}^{2+}$ e $1 \mathrm{~g}$ de consórcio bacteriano apenas liofilizado. Os erlenmeyers foram agitados em um shaker a uma velocidade constante de $150 \mathrm{rpm}$ e temperatura de $28^{\circ} \mathrm{C}$.

\subsubsection{Parâmetros analisados}

Os parâmetros analisados foram $\mathrm{pH} 2,4$ e $6 . \mathrm{O}$ ajuste do $\mathrm{pH}$ ocorreu com a adição de $\mathrm{HCl} 1 \mathrm{M}$ e NaOH . As amostras foram coletadas nos tempos: 0 (padrão antes da adição de bactérias); 0 (padrão após a adição de bactérias); 1 minuto; 5 minutos; 20 minutos; 60 minutos; 90 minutos e 120 minutos. Depois disso, $0,5 \mathrm{~mL}$ das amostras foram colocadas em eppendorfs, que foram centrifugados, separando $O$ sobrenadante da bactéria. A bactéria peletada foi descartada, e o sobrenadante foi coletado por meio de agulha e seringa, para posterior filtragem em filtro de membrana de 0,45 $\mu \mathrm{m}$ e o armazenamento em eppendorfs. Após esse processo de filtragem, as amostras foram armazenadas em um refrigerador, até a etapa de digestão de amostras.

\subsection{Digestão de amostras}

A digestão das amostras ocorreu por meio de micro-ondas próprio para essa finalidade, e o método adotado nas digestões das amostras foi o EPA 1530. 


\subsection{Análise das concentrações de metal}

A análise das concentrações de metais foi realizada por meio do ICP-OES. Todas as análises apresentaram uma curva de calibração do metal, com o objetivo de garantir precisão nas intensidades dos resultados analisados.

Descrever brevemente os equipamentos e os procedimentos utilizados, assim como a literatura e os métodos estatísticos empregados, quando for o caso.

\section{RESULTADOS E DISCUSSÃO}

A porcentagem de remoção do metal do meio $(\mathrm{R}(\%))$ foi calculado de acordo com a equação (1).

$$
\mathrm{R}(\%)=\frac{C i-C f}{C i} \times 100
$$

Em que:

R é a percentagem de remoção do metal do meio;

Ci é a concentração inicial do metal em $\left(\mathrm{mg} \cdot \mathrm{L}^{-1}\right)$;

Cf é a concentração final do metal em (mg. $\left.\mathrm{L}^{-1}\right)$.

O cálculo da capacidade de captura metálica (qe), foi calculado de acordo com a equação (2).

Em que:

$$
\mathrm{q}_{\mathrm{e}}=\frac{C i-C e}{m} \times \mathrm{V}
$$

qe é a capacidade de captura de metal ( $\mathrm{mg}$ de metal/g de biossorvente);

Ci é a concentração inicial de metal $\left(\mathrm{mg}^{\mathrm{L}} \mathrm{L}^{-1}\right)$;

Ce é a concentração de metal no sistema de equilíbrio $\left(\mathrm{mg}^{\mathrm{L} \mathrm{L}^{-1}}\right)$;

$M$ é a massa ( $\mathrm{g}$ ) do biossorvente pesado na balança;

$\checkmark$ é o volume da solução utilizada no erlenmeyer (litros).

A Figura 1 mostra a curva de calibração de $\mathrm{Ni}^{2+}$. 


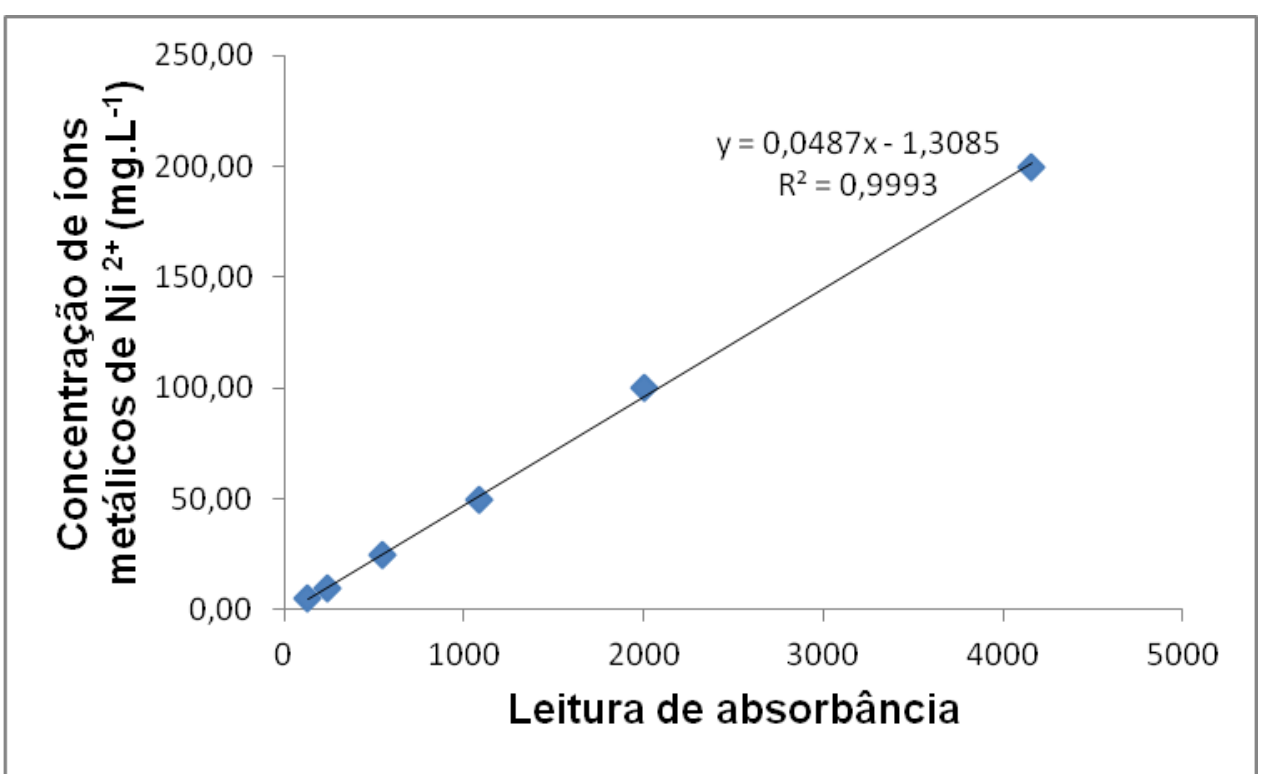

Figura 1. Curva de calibração de $\mathrm{Ni}^{2+}$.

A Figura 2 mostra a porcentagem de remoção de íons de níquel no teste com concentração de $\mathrm{Ni}^{2+}$ de $100 \mathrm{mg} \cdot \mathrm{L}^{-1}$, concentração de biomassa de $1 \mathrm{~g} \cdot \mathrm{L}^{-1}$ e valores de $\mathrm{pH}=2$, 4 e 6 . Já os valores de qe são apresentados na Figura 3.

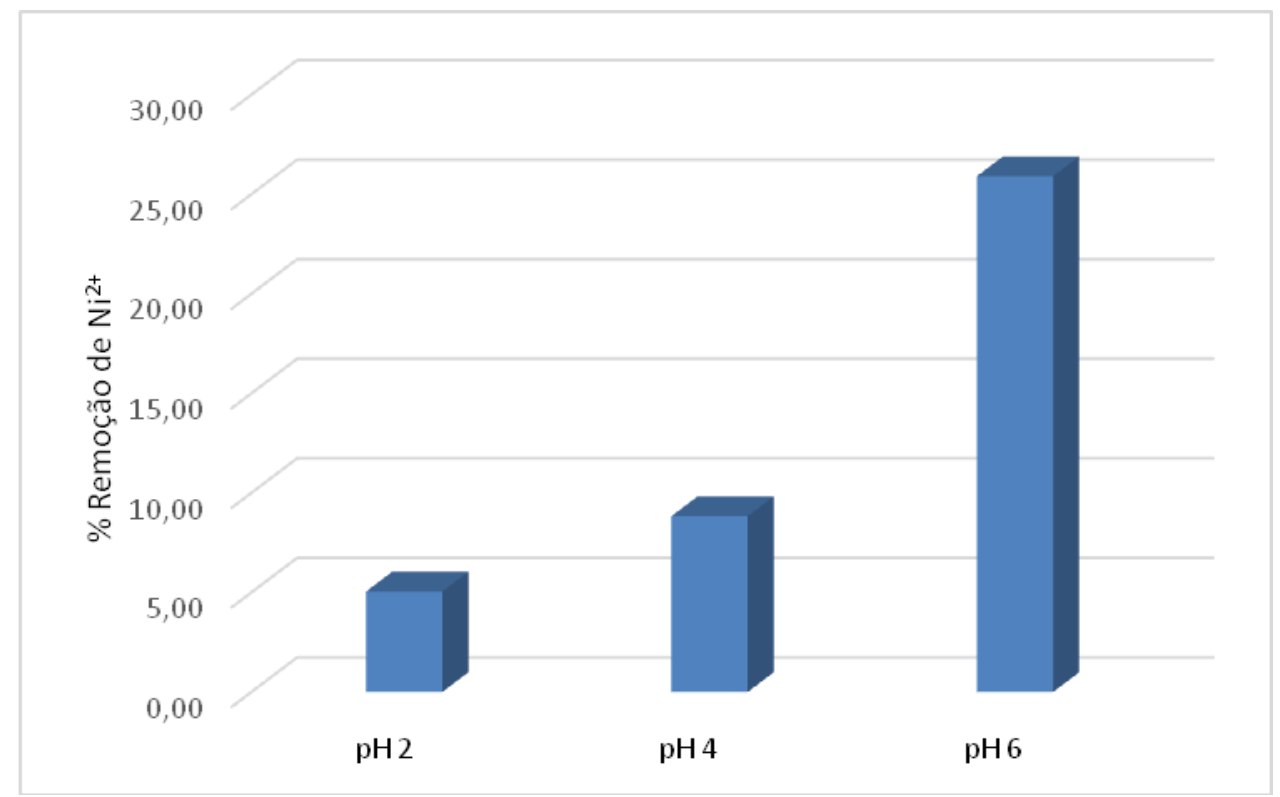

Figura 2. Porcentagem de remoção de $\mathrm{Ni}^{2+}$ para $\mathrm{pH} 2,4$, e 6 


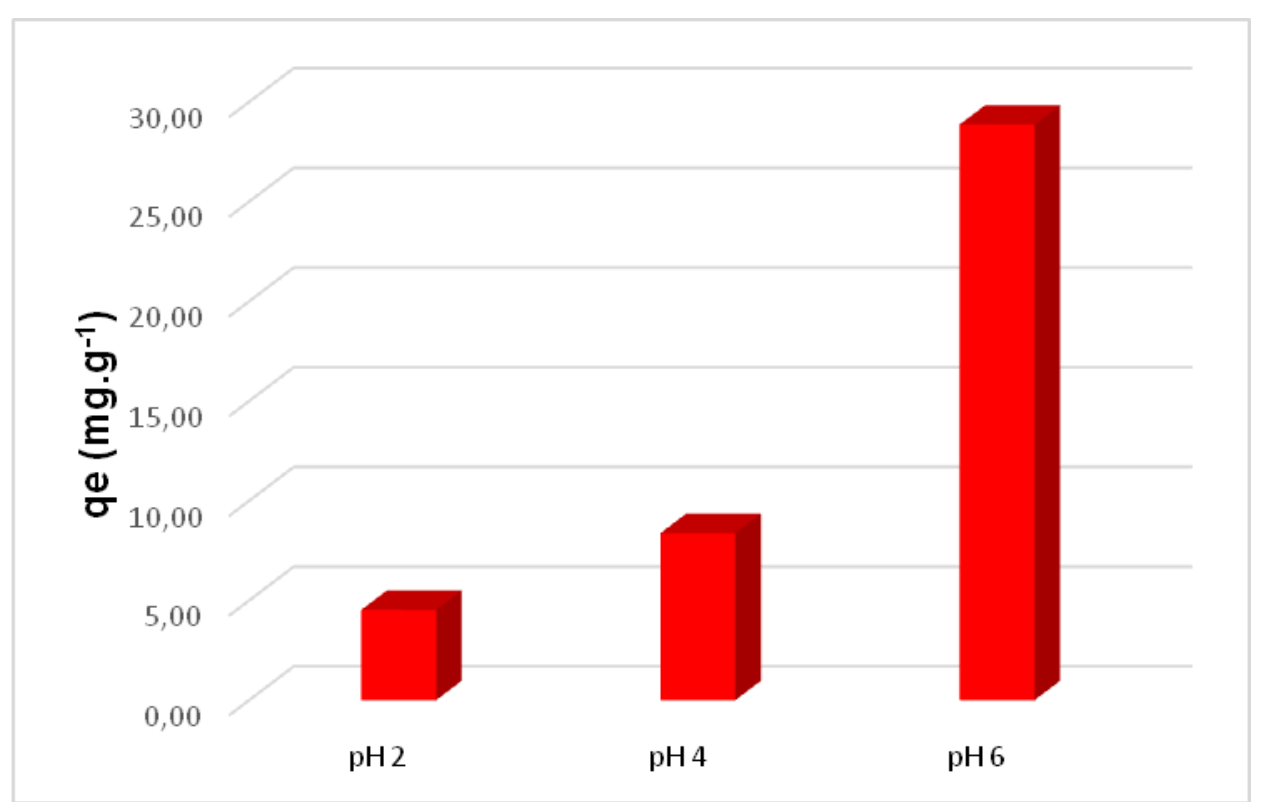

Figura 3. Valores de qe $\left(\mathrm{mg}^{-g^{-1}}\right)$ para $\mathrm{pH} 2,4$ e 6

Os resultado possibilitaram verificar no $\mathrm{pH} 2$ a faixa de remoção foi de cerca de $5,04 \%$, no pH 4 em torno de 8,83 e em pH 6 a remoção de $\mathrm{Ni}^{2+}$ foi maior, na faixa de 25,90 . Estes resultados indicam que a biossorção foi mais eficiente para maiores valores de $\mathrm{pH}$.

A explicação da carga global negativa de bactérias está em função de propriedades contidas nesses micro-organismos. Ácidos teicoicos e lipopolissacarídeos conferem carga global negativa na célula (11). Assim, esse é um dos fatores para que ocorra a ligação de íons de metais na superfície de bactérias. Em valores menores de $\mathrm{pH}$, os locais de ligação da superfície celular são protonizados (12).

Outra discussão é a utilização de consórcio bacteriano isolado da terra. O consórcio do presente estudo foi eficiente no processo de biossorção. No presente estudo, a qe em pH 2 foi de cerca de 4,53, no pH 4 em torno de 8,38 e para pH 6 em torno de 28,87. Ou seja, os valores obtidos no presente estudo estão de acordo com a literatura referente ao metal níquel, devido, por exemplo, outro estudo que conseguiu uma capacidade máxima de biossorção de $\mathrm{Ni}^{2+}$ de $8.56 \mathrm{mg} \mathrm{g}^{-1} \mathrm{com}$ o pH 5 por meio da utilização de R. opacus (13). No entanto, essa discussão apresenta valores que são apenas uma representação relativa, devido as diferentes condições e parâmetros que os trabalhos abordaram. Os resultados do presente estudo contribuíram na possibilidade de aplicação de bactérias como biossorventes na remoção de íons metálicos de $\mathrm{Ni}^{2+}$, e assim, comprovou que a técnica de biossorção apresenta não só a eficiência de remoção de íons metálicos de efluentes, mas também ideias na utilização de diversos biossorventes que possam ser aplicados e que merecem ser cada vez mais estudados.

\section{CONCLUSÃO}

Concluiu-se que:

a) A biossorção é uma técnica que não necessita da produção especial de um biossorvente; 
b) O simples fato do consorcio bacteriano no presente estudo não ter sido autoclavado (matado totalmente as bactérias) e ter sido apenas liofilizado (matado parcialmente as bactérias), indica que diversos cultivos bacterianos de indústrias podem ser aplicados nessa técnica;

c) Os resultados confirmaram que a biossorção mais eficiente ocorreu com o pH 6 , que foi o maior valor de $\mathrm{pH}$ do estudo, estando assim, de acordo com a literatura;

d) O parâmetro qe deve ser analisado (e não apenas a porcentagem de remoção de metal), uma vez que o qe informa o quanto de metal (mg) foi adsorvido por um grama de biossorvente.

\section{Agradecimentos}

Os autores agradecem o apoio financeiro do CAPES PROEX nos processos 3300201 e AO Projeto Temático da FAPESP processo 2012/51871-9.

\section{REFERÊNCIAS}

1. Garcia X, Pargament D. Reusing wastewater to cope with water scarcity: Economic, social and environmental considerations for decision-making. Resour Conserv Recycl. 2015;101:154-66.

2. DeBoer J, Linstedt KD. Advances in water reuse applications. Water Res. 1985;19(11):1455-1461.

3. Prieto D, Swinnen N, Blanco L, Hermosilla D, Cauwenberg P, Blanco Á, et al. Drivers and economic aspects for the implementation of advanced wastewater treatment and water reuse in a PVC plant. Water Resour Ind. 2016;14:26-30.

4. Piratla KR, Goverdhanam S. Decentralized Water Systems for Sustainable and Reliable Supply. Procedia Eng. 2015;118:720-6.

5. Nongmaithem N, Roy A, Bhattacharya PM. Screening of Trichoderma isolates for their potential of biosorption of nickel and cadmium. Brazilian J Microbiol. 2016;47(2):305-13.

6. Ma Y, Rajkumar M, Freitas H. Improvement of plant growth and nickel uptake by nickel resistant-plant-growth promoting bacteria. $\mathrm{J}$ Hazard Mater. 2009;166(2-3):1154-61.

7. Congeevaram S, Dhanarani S, Park J, Dexilin M, Thamaraiselvi K. Biosorption of chromium and nickel by heavy metal resistant fungal and bacterial isolates. $J$ Hazard Mater. 2007;146(1-2):270-7.

8. Li C, Champagne P. Fixed-bed column study for the removal of cadmium (II) and nickel (II) ions from aqueous solutions using peat and mollusk shells. $J$ Hazard Mater. 2009;171(1-3):872-8.

9. Wang J, Chen C. Biosorption of heavy metals by Saccharomyces cerevisiae: A review. Biotechnol Adv. 2006;24(5):427-51.

10. Kratochvil D, Volesky B. Advances in the biosorption of heavy metals. Trends Biotechnol. 1998;16(7):291-300.

11. Vijayaraghavan K, Yun YS. Bacterial biosorbents and biosorption. Biotechnol 
Adv. 2008;26(3):266-91.

12. $\mathrm{Xu} \mathrm{H}$, Liu $\mathrm{Y}$, Tay JH. Effect of $\mathrm{pH}$ on nickel biosorption by aerobic granular sludge. Bioresour Technol. 2006;97(3):359-63.

13. Cayllahua JEB, de Carvalho RJ, Torem ML. Evaluation of equilibrium, kinetic and thermodynamic parameters for biosorption of nickel(II) ions onto bacteria strain, Rhodococcus opacus. Miner Eng [Internet]. Elsevier Ltd; 2009;22(15):1318-25. Available from: http://dx.doi.org/10.1016/j.mineng.2009.08.003. 